\title{
Endogenous opioids modify dyspnoea during treadmill exercise in patients with COPD
}

\author{
D.A. Mahler*, J.A. Murray", L.A. Waterman", J. Ward", W.J. Kraemer ${ }^{+}$, \\ X. Zhang* and J.C. Baird*\$,
}

ABSTRACT: Exogenous opioid drugs, such as morphine, relieve breathlessness. The present study hypothesis was that endogenous opioids, released during the stress of exercise, modify dyspnoea in patients with chronic obstructive pulmonary disease.

After familiarisation, patients performed an incremental treadmill exercise test followed by constant work on the treadmill for $10 \mathrm{~min}$. At subsequent visits ( 2 to 3 days apart), patients received two puffs of albuterol, had a catheter placed in an arm vein for removal of blood to measure $\beta$-endorphin immunoreactivity, received normal saline or $10 \mathrm{mg}$ of naloxone intravenously in randomised order, and then performed high-intensity constant work rate exercise on the treadmill.

The mean \pm SD age of the 17 patients (eight females and nine males) was $63 \pm 7$ yrs, and postbronchodilator forced expiratory volume in one second was $50 \pm 17 \%$ predicted. In both conditions, $\beta$-endorphin levels increased three-fold from rest to end-exercise. The regression slope of breathlessness as a function of oxygen consumption (primary outcome), mean ratings of breathlessness throughout exercise and peak ratings of breathlessness were significantly higher with naloxone than normal saline. There were no differences in physiological responses throughout exercise between conditions.

In conclusion, endogenous opioids modify dyspnoea during treadmill exercise in patients with chronic obstructive pulmonary disease by apparent alteration of central perception.

KEYWORDS: $\beta$-endorphin immunoreactivity, chronic obstructive pulmonary disease, continuous ratings of breathlessness, naloxone, treadmill exercise

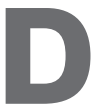

yspnoea, or breathlessness, is the most frequent symptom of patients with chronic obstructive pulmonary disease (COPD). Based on a neurophysiological model, breathlessness occurs when sensory receptors involved with respiration are activated and send an afferent impulse to the central nervous system (CNS). After integration and processing of this signal, the CNS directs an efferent impulse towards the muscles of respiration. Any alteration of the sensory receptors, the CNS and/or the respiratory muscles could lead to a dissociation or "mismatch" between outgoing motor signals from the CNS and the mechanical response of the respiratory system, and thereby contribute to breathlessness [1].

Exogenous opioid drugs, such as dihydrocodeine and morphine, reduce the intensity of exertional breathlessness in patients with COPD [2, 3]. In 1985, SANTIAGo and Edelman [4] postulated that endogenous opioids might be elaborated as a protective mechanism to relieve breathing difficulty when respiratory distress occurred. Naloxone, an opioid antagonist, has been used in numerous studies to examine the putative role of endorphins on breathing. Using hypoxia, hypercapnia, inspiratory resistance breathing and exercise on the cycle ergometer as respiratory stimuli, investigators have been unable to demonstrate an effect of endorphins on respiration and/or breathlessness in patients with COPD [5-7]. In one study SANTIAGO et al. [8] reported that naloxone restored the ventilatory responses to an added inspiratory flow-resistive load in seven of the 14 patients with COPD in whom "load compensation" was absent.

In the present study, the hypothesis that endogenous opioids modify the severity of exertional breathlessness in patients with symptomatic COPD was examined. A secondary hypothesis
AFFILIATIONS

*Section of Pulmonary and Critical Care Medicine, Dartmouth Medical School, Hanover, $\mathrm{NH}$

"Pulmonary Function and Cardiopulmonary Exercise Laboratories, Dartmouth-Hitchcock Medical Center, Lebanon, NH, \#Unity Health System, Rochester, NY,

+University of Connecticut, Storrs, $\mathrm{CT}$, and

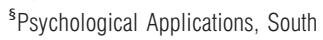
Pomfret, VT, USA.

CORRESPONDENCE

D.A. Mahler, Section of Pulmonary and Critical Care Medicine, Dartmouth-Hitchcock Medical Center, One Medical Center Drive Lebanon, NH 03756-0001, USA. Fax: 16036500580

E-mail: Donald.a.mahler@ hitchcock.org

Received:

September 232008 Accepted after revision: December 012008

\section{SUPPORT STATEMENT}

This study is a clinical trial registered with www.clinicaltrials.gov (NCT00458419).

\section{STATEMENT OF INTEREST}

A statement of interest for J.C. Baird can be found at

www.erj.ersjournals.com/misc/ statements.dt 
was that patients would exercise longer with normal saline compared with blockade of the endogenous opioid system. The study design incorporated different methodology from that used previously to examine these hypotheses. Constant work rate on the treadmill rather than cycle ergometry was used as the exercise stimulus, because walking is a relevant daily activity and provokes breathlessness to a greater extent than does cycling in patients with COPD $[9,10]$. The speed and incline of treadmill exercise were individualised so that each patient walked for at least $10 \mathrm{~min}$ in an attempt to provide an adequate respiratory challenge. Patients reported the actual course of breathlessness throughout exercise using a continuous rating system rather than providing ratings "on cue" at discrete time-points [11]. Preliminary results of the current study have been presented as an abstract [12].

\section{MATERIALS AND METHODS \\ Subjects}

Patients with a diagnosis of COPD were recruited from the out-patient clinics at the Dartmouth-Hitchcock Medical Center (Lebanon, NH, USA). The protocol was approved by the Committee for the Protection of Human Subjects at Dartmouth College (Hanover, NH). All patients provided informed written consent. Inclusion criteria were: $\geqslant 50$ yrs of age; diagnosis of COPD [13]; self-reported rating of breathlessness on the baseline dyspnoea index (BDI) of $\leqslant 8[14] ; \geqslant 10$ pack-yr history of cigarette smoking; ability to exercise on the treadmill; and clinically stable.

As there is limited information available about a relevant difference in the regression slope between breathlessness and oxygen consumption $\left(V^{\prime} \mathrm{O}_{2}\right.$; the primary outcome), the current authors used a rating of breathlessness of \pm 1 with an SD of 1 at a standardised work rate as an estimate to calculate the sample size [15]. A sample size of 16 was used to provide the power $(80 \%)$ to detect a significant difference in standardised breathlessness ratings, with $\alpha=0.05$.

\section{Study design}

The main objective was to compare the effects of i.v. administration of normal saline and naloxone on ratings of dyspnoea during constant work rate treadmill exercise. The study design was randomised and double blind. After familiarisation with equipment and procedures, each patient performed spirometry (Collins model CPL; NSpire, Longmont, $\mathrm{CO}, \mathrm{USA}$ ) and an incremental treadmill (Full Vision Inc., Newton, KS, USA) exercise test using a modified Balke protocol [16]. After a 1-h rest, each patient walked on the treadmill to establish the speed and incline for the constant work rate exercise used at subsequent testing. The treadmill speed was the same as obtained for each patient during the incremental exercise test, while the incline of the treadmill was adjusted so that the patient could exercise for $10 \mathrm{~min}$ at a high intensity of breathlessness [11].

There were two intervention study visits, 2 to 3 days apart. Patients were instructed not to take any inhaled medications for $12 \mathrm{~h}$ and to avoid caffeine for $4 \mathrm{~h}$ prior to each visit. Testing was performed at the same time of day for each subject. Patients performed spirometry before and $30 \mathrm{~min}$ after inhaling two puffs of albuterol $(180 \mu \mathrm{g})$. Predicted values for spirometry were taken from CRAPO et al. [17]. An 18-gauge catheter was inserted into an arm vein for measurement of $\beta$ endorphin immunoreactivity. The subject sat in a chair while breathing quietly through the mouthpiece for $5 \mathrm{~min}$. After $10 \mathrm{~mL}$ of venous blood was removed, normal saline $(25 \mathrm{~mL})$ or naloxone (10 $\mathrm{mg}$ in $25 \mathrm{~mL}$ total volume) was administered i.v. in random order. Patients continued to breathe quietly through the mouthpiece for $5 \mathrm{~min}$ and then performed a symptomlimited constant work exercise test according to recommended guidelines [16]. Each patient was strongly encouraged to exercise for "as long as possible" with a target of $10 \mathrm{~min}$ as a minimum. The exercise tests were terminated when the patient indicated that he/she could no longer continue. At the end of each exercise test the patient was asked "Why did you stop exercise: breathlessness, leg discomfort, or both?"

Expired gas was analysed for minute ventilation $\left(V^{\prime} \mathrm{E}\right), V^{\prime} \mathrm{O}_{2}$ and carbon dioxide production $\left(V^{\prime} \mathrm{CO}_{2}\right)$ at rest and throughout exercise using a metabolic measurement system (MedGraphics Cardiorespiratory Diagnostic Systems, St Paul, MN, USA). The system was calibrated before each test. Oxygen saturation was recorded using a pulse oximeter (Nellcor Inc., Hayward, CA, USA).

The patient rated breathlessness and leg discomfort throughout exercise using a continuous method that utilised a computer, a monitor and a mouse, as previously described [11]. At each visit, the patient read the following written instructions. "This is a scale for rating breathlessness and leg discomfort. The number 0 represents no breathlessness and no leg discomfort. The number 10 represents the strongest or greatest breathlessness or leg discomfort that you have ever experienced. You should adjust the length of the blue bar to represent your perceived level of breathlessness by pressing the left button on the mouse. You should adjust the length of the red bar to represent your perceived level of leg discomfort by pressing the right button on the mouse. Use the written descriptions to the right of the numbers to help guide your selection. You should increase the length of each bar whenever you experience a change in breathlessness or leg discomfort."

To measure $\beta$-endorphin immunoreactivity, $10 \mathrm{~mL}$ of venous blood were removed from the catheter using a chilled syringe and then immediately emptied into chilled tubes containing EDTA anticoagulant, while the patient was seated in a chair on three occasions (after $5 \mathrm{~min}$ of rest, within $1 \mathrm{~min}$ of completion of exercise, and $30 \mathrm{~min}$ after completion of exercise). With these specimens, plasma $\beta$-endorphin immunoreactivity was measured using a Beckman Gamma 5500 System (Beckman Instruments, Fullerton, CA, USA) with data processor, as previously described [18].

\section{Statistical analysis}

The primary outcome was the regression slope between breathlessness and $V^{\prime} \mathrm{O}_{2}[15,19,20]$. Secondary outcomes were peak and mean ratings of breathlessness throughout exercise, exercise duration, the regression slope between breathlessness and $V^{\prime} E$, and plasma $\beta$-endorphin immunoreactivity.

Paired t-tests were used to compare outcomes. The Pearson correlation coefficient was used to examine differences in mean ratings of breathlessness and differences in exercise time between the two conditions. All data are reported as 


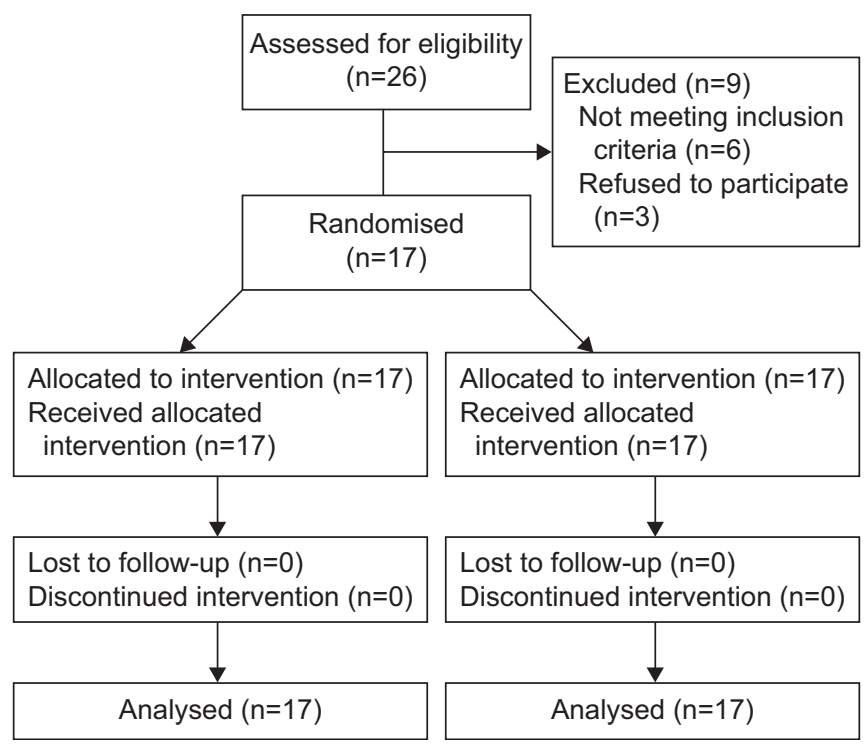

FIGURE 1. Diagram of enrolment, allocation, follow-up and analysis of patients

mean \pm SD. A p-value $\leqslant 0.05$ (two-tailed test) was considered statistically significant.

\section{RESULTS}

In total, 17 patients (eight females and nine males) participated in the present study (fig. 1). The mean \pm SD age was $63 \pm 7$ yrs, height was $168 \pm 8 \mathrm{~cm}$ and weight was $74 \pm 14 \mathrm{~kg}$. As a group, the patients reported moderate breathlessness related to activities of daily living on the self-administered computerised BDI $(5.7 \pm 1.4)$. Respiratory medications were albuterol metered dose inhaler $(n=17)$, inhaled long-acting $\beta$-agonist $(n=11)$, inhaled short- or long-acting anticholinergic medication $(n=14)$, inhaled corticosteroids $(n=8)$ and oral theophylline $(n=3)$. The results of lung function measurements are given in table 1.

The number of patients in the different stages of COPD based on post-bronchodilator forced expiratory volume in one second (FEV1) \% predicted [13] were as follows. II: eight; III: eight; IV: one. There were no significant differences for pre- or post-bronchodilator values for lung function between the two visits.

Resting values for heart rate and for respiratory variables were similar between naloxone and normal saline. Results from constant work treadmill exercise (speed $1.9 \pm 0.8$ miles $\cdot h^{-1}$ $\left(3.06 \pm 1.29 \mathrm{~km} \cdot \mathrm{h}^{-1}\right)$; grade $\left.3.8 \pm 2.1 \%\right)$ are presented in table 2 .

There were no differences in $V^{\prime} \mathrm{O}_{2}$ or $V^{\prime} \mathrm{E}$ values when compared every $2 \mathrm{~min}$ throughout constant work rate exercise under the two conditions (fig. 2). Peak physiological variables were similar between naloxone and normal saline. The highest $V^{\prime} \mathrm{O}_{2}$ values represented $92 \%$ of peak $V^{\prime} \mathrm{O}_{2}\left(16.7 \pm 5.4 \mathrm{~mL} \cdot \mathrm{kg} \cdot \mathrm{min}^{-1}\right)$ obtained during the incremental treadmill exercise test. The mean ratio of peak $V^{\prime} \mathrm{E}$ to the calculated maximal voluntary ventilation $(\mathrm{FEV} 1 \times 40)$ was $82 \%$. Individual values for the slope of breathlessness and $V^{\prime} \mathrm{O}_{2}$ are shown in figure 3. Paired t-testing showed that the regression slope of breathlessness and $V^{\prime} \mathrm{O}_{2}$ was significantly higher with naloxone than with normal saline $(\mathrm{p}=0.02)$. This difference remained statistically

\begin{tabular}{lcc}
\hline TABLE 1 & Results of lung function & \\
& Naloxone & Normal saline \\
\hline FVC & & \\
L & & \\
$\%$ pred & $3.05 \pm 0.70$ & $3.01 \pm 0.62$ \\
FEV 1 & $84 \pm 14$ & $83 \pm 12$ \\
Baseline & & \\
L & $1.15 \pm 0.36$ & $1.14 \pm 0.35$ \\
$\%$ pred & $45 \pm 15$ & $45 \pm 14$ \\
Post-BD & & \\
L & $1.27 \pm 0.39$ & $1.24 \pm 0.34$ \\
\% pred & $50 \pm 17$ & $49 \pm 15$ \\
Post-BD FEV $\mathbf{1} / \mathbf{F V C} \%$ & $39 \pm 12$ & $39 \pm 11$ \\
\hline
\end{tabular}

Data are presented as mean \pm SD. FVC: forced vital capacity; \% pred: \% predicted; FEV1: forced expiratory volume in one second; BD: bronchodilator.

significant after elimination of one patient (stage II disease) who exhibited the greatest difference between naloxone and normal saline. Peak ratings of breathlessness were significantly higher with naloxone compared with normal saline $(p=0.05)$. Individual differences in mean ratings of breathlessness throughout exercise between naloxone and normal saline were significant ( $p=0.04$; fig. 4$)$. There was a trend showing a greater exercise time with normal saline compared with

\begin{tabular}{|c|c|c|c|}
\hline & Naloxone & $\begin{array}{c}\text { Normal } \\
\text { saline }\end{array}$ & p-value $(95 \% \mathrm{Cl})$ \\
\hline \multicolumn{4}{|l|}{ Peak values } \\
\hline$V^{\prime} \mathrm{O}_{2} \mathrm{~mL} \cdot \mathrm{kg} \cdot \mathrm{min}^{-1}$ & $15.5 \pm 5.2$ & $15.3 \pm 5.4$ & $0.22(-0.17-0.71)$ \\
\hline$V^{\prime} E L \cdot \min ^{-1}$ & $36.5 \pm 12.4$ & $35.7 \pm 12.5$ & $0.18(-0.42-2.08)$ \\
\hline$V^{\prime} \mathrm{CO}_{2} \mathrm{~L} \cdot \mathrm{min}^{-1}$ & $1.0 \pm 0.3$ & $1.0 \pm 0.3$ & $0.60(-0.03-0.06)$ \\
\hline$f R$ breaths $\cdot \mathrm{min}^{-1}$ & $34 \pm 9$ & $34 \pm 10$ & $0.76(-1.83-1.34)$ \\
\hline$f_{C}$ beats $\cdot \mathrm{min}^{-1}$ & $129 \pm 18$ & $130 \pm 16$ & $0.19(-1.55-4.12)$ \\
\hline $\mathrm{Sa}_{1} \mathrm{O}_{2} \%$ & $92.5 \pm 3.3$ & $91.8 \pm 4.2$ & $0.07(-1.64-0.26)$ \\
\hline Breathlessness & $8.7 \pm 2.3$ & $8.0 \pm 2.3$ & $0.05(-0.00-1.42)$ \\
\hline Leg discomfort & $5.9 \pm 3.2$ & $5.5 \pm 3.3$ & $0.27(-0.37-1.23)$ \\
\hline Endurance time min & $12.33 \pm 4.08$ & $14.02 \pm 4.08$ & $0.058(-101-177)$ \\
\hline \multicolumn{4}{|l|}{$\begin{array}{l}\text { Reason for stopping } \\
\text { exercise } n\end{array}$} \\
\hline Breathlessness & 15 & 15 & \\
\hline Leg discomfort & 2 & 2 & \\
\hline \multicolumn{4}{|l|}{ Regression slopes } \\
\hline Breathlessness $-V^{\prime} \mathrm{O}_{2}$ & $3.34 \pm 1.93$ & $2.51 \pm 2.10$ & $0.02(0.13-1.53)$ \\
\hline Breathlessness- $V^{\prime} E$ & $0.87 \pm 1.00$ & $0.76 \pm 0.88$ & $0.32(-0.47-0.71)$ \\
\hline Leg discomfort- $-V^{\prime} \mathrm{O}_{2}$ & $2.23 \pm 1.66$ & $1.86 \pm 1.69$ & $0.38(-0.49-1.22)$ \\
\hline
\end{tabular}

Data are presented as mean $\pm \mathrm{SD}$, unless otherwise stated. $\mathrm{Cl}$ : confidence interval; $\mathrm{V}^{\prime} \mathrm{O}_{2}$ : oxygen consumption; $V^{\prime} \mathrm{E}$ : minute ventilation; $\mathrm{V}^{\prime} \mathrm{CO}_{2}$ : carbon dioxide production; $f R$ : respiratory frequency; $f C$ : cardiac frequency; $\mathrm{Sa}_{1} \mathrm{O}_{2}$ arterial oxygen saturation. 

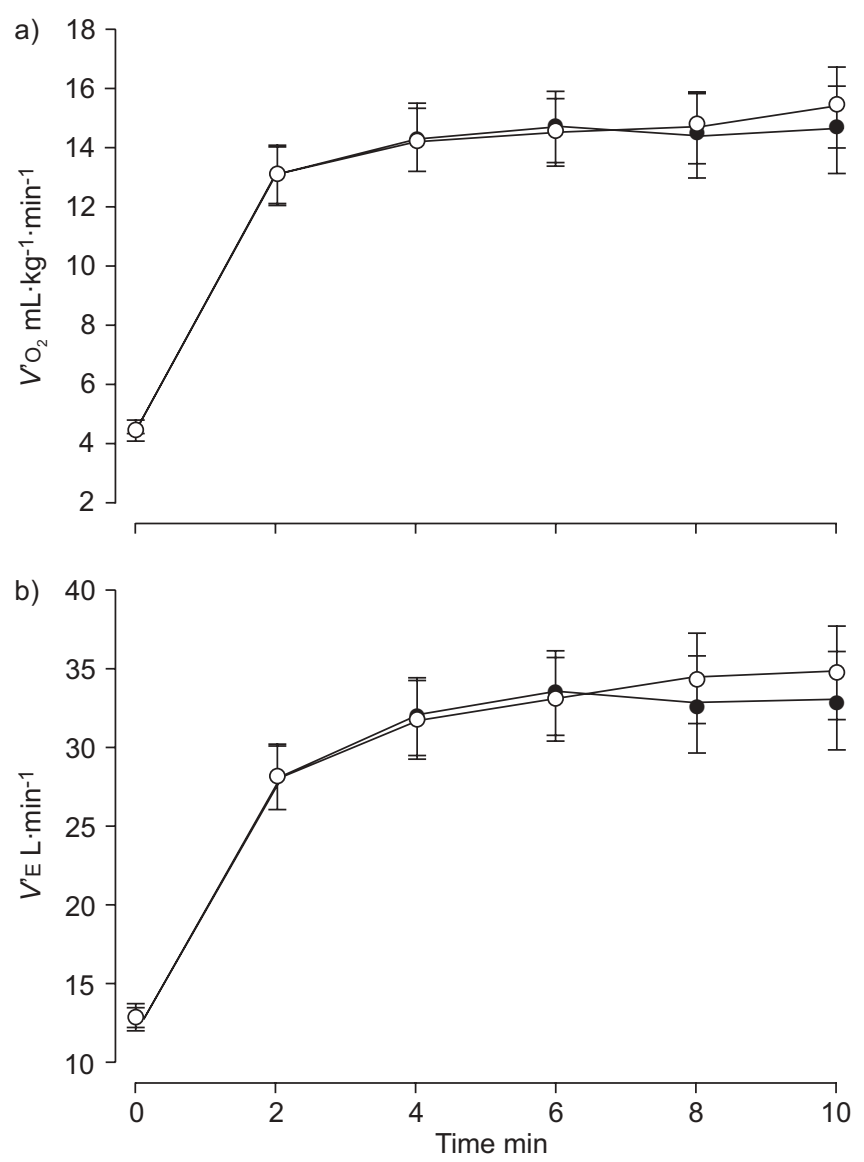

FIGURE 2. Mean and SE values for a) oxygen consumption $\left(V^{\prime} \mathrm{O}_{2}\right)$ and b) minute ventilation $\left(V^{\prime} E\right)$ every 2 min during the first 10 min of constant work rate exercise on the treadmill. There were no differences for $V^{\prime} \mathrm{O}_{2}$ and $V^{\prime} E$ at any timepoints between naloxone $(\bullet)$ and normal saline $(\bigcirc)$. For time-points 0-6 min, $\mathrm{n}=17$ for each group. At 8 and $10 \mathrm{~min}, \mathrm{n}=14$ for the naloxone group and $\mathrm{n}=17$ for the normal saline group.

naloxone (difference of $1.68 \mathrm{~min} ; \mathrm{p}=0.058$ ). There was no difference in the slope of breathlessness and $V^{\prime} \mathrm{E}$ between treatments. The correlation between differences in mean ratings of breathlessness and differences in exercise time was -0.07 .

Table 3 shows the levels of $\beta$-endorphin immunoreactivity at the three time-points. Patients exhibited an increase in $\beta$ endorphin immunoreactivity from rest to peak exercise $(\mathrm{p}<0.001)$, and a decrease post exercise compared with peak values $(p<0.001)$. There were no significant differences in $\beta$ endorphin immunoreactivity at corresponding time-points between naloxone and normal saline.

\section{DISCUSSION}

The major findings of the present study were: 1) patients reported greater breathlessness during exercise with naloxone compared with normal saline; 2) plasma $\beta$-endorphin levels increased similarly during exercise with naloxone and normal saline; 3) there was a nonsignificant trend for patients to exercise longer with normal saline compared with naloxone.

Endogenous opioids are widely distributed in areas of the CNS and act as neurotransmitters of a complex inhibitory system [4].

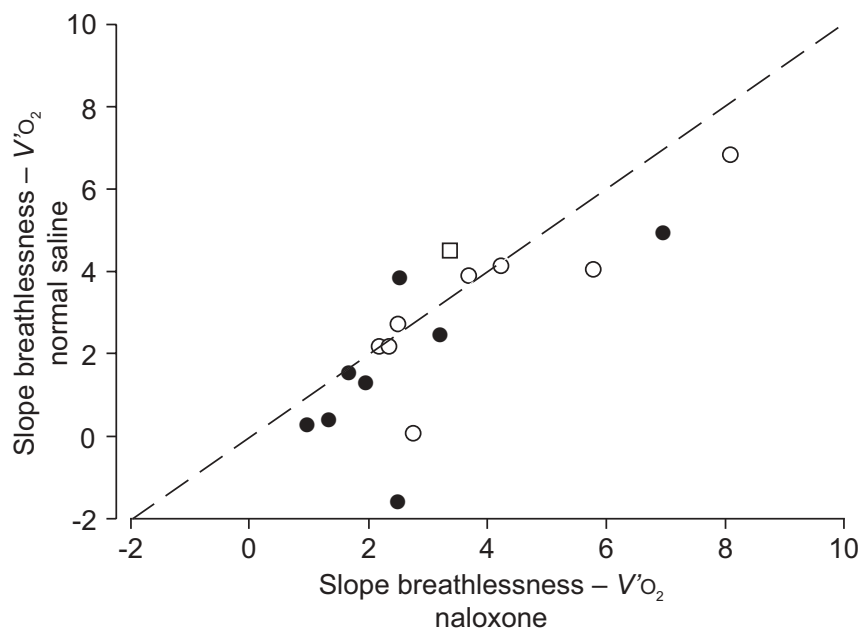

FIGURE 3. Individual values for the regression slope of breathlessness and oxygen consumption $\left(\mathrm{V}^{\prime} \mathrm{O}_{2}\right)$ with administration of naloxone and normal saline. - - - : line of identity. Paired t-tests showed a significant difference between naloxone and normal saline $(p=0.02)$. Individual patients are identified by their stage of disease severity based on \% predicted values for forced expiratory volume in one second [13]. ๑: stage II; O: stage III; $\square$ : stage IV.

Of the five groups of naturally occurring opioid peptides, $\beta$ endorphins contribute to pain perception, and have been widely studied in regard to respiration [4,21]. Both circulating $\beta$ endorphins, which are produced by the pituitary gland, and levels found in the cerebrospinal fluid, which are elaborated in the brain, increase in response to strenuous exercise in healthy individuals [21]. To the current authors' knowledge, the present study is the first to report the response of circulating $\beta$ endorphins to exercise in patients with COPD. When injected into the vicinity of the medulla in animals, $\beta$-endorphins depress breathing primarily by reducing tidal volume [22]. This response is similar to the effect of oral morphine in humans [23].

Naloxone, an opioid antagonist that readily crosses the bloodbrain barrier, has been used to uncover the putative effects of endogenous opioids. In the present study, patients with COPD reported higher ratings of breathlessness throughout treadmill exercise after administration of naloxone compared with normal saline. The variability of individual responses is illustrated in figures 3 and 4 . The current authors prospectively selected the regression slope between breathlessness and $V^{\prime} \mathrm{O}_{2}$ as the primary outcome measure for several reasons. First, this parameter represents a continuum of the relationship between overall metabolic activity and the perception of breathlessness. It provides more comprehensive information compared with a single rating at exercise isotime or at endexercise. Secondly, the regression slope between breathlessness and $V^{\prime} \mathrm{O}_{2}$ during exercise is an established metric that has been used by investigators to discriminate between different populations and to examine treatment effects in patients with COPD [11, 15, 20]. Thirdly, the regression slope between continuous ratings of breathlessness and $V^{\prime} \mathrm{O}_{2}$ has demonstrated responsiveness [19]. The actual value for the regression slope between breathlessness and $V^{\prime} \mathrm{O}_{2}$ with normal saline, used as a control condition in the current study, approximated 


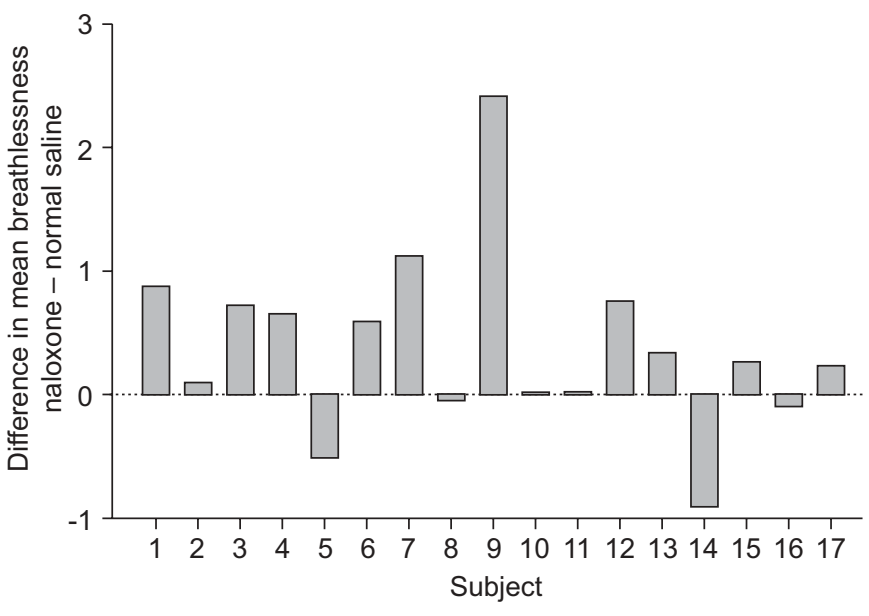

FIGURE 4. Individual differences in mean ratings of breathlessness throughout exercise between naloxone and normal saline. Paired t-tests showed a significant difference between naloxone and normal saline $(p=0.04)$. Patients provided similar numbers of ratings of breathlessness throughout exercise with naloxone and with normal saline $(20.9 \pm 7.2$ versus $20.1 \pm 7.5$, respectively; $p=0.47)$.

the value obtained previously when patients with COPD performed incremental treadmill exercise [24].

The higher ratings of breathlessness at peak exercise (table 2) and mean ratings throughout exercise (fig. 4) after administration of naloxone support the results of the primary outcome. The display of individual differences in mean ratings of breathlessness is a novel approach that reflects the collective experience of breathlessness reported by patients throughout exercise. The current data complement the usual method of calculating the regression slope between breathlessness and $V^{\prime} \mathrm{O}_{2}$. It was not possible to display plots of breathlessness against time or $V^{\prime} \mathrm{O}_{2}$ because the continuous reporting method made it difficult to anchor symptom ratings to a specific physiological stimulus.

To the current authors' knowledge, the present study is the first to demonstrate that endorphins modulate exertional breathlessness. Although there has been wide interest in the role of endorphins in breathing for some time, previous investigators failed to show any direct effect. For example, KIRSCH et al. [5] reported no differences in perceptual responses between naloxone and normal saline in six patients with COPD who performed incremental cycle ergometry and rated breathlessness each minute of the test. In a preliminary report, BERTLEY et al. [6] found that five out of 12 patients with COPD were "responders" based on their increased ratings of breathlessness after receiving naloxone compared with normal saline.

Although the present study examined the same hypothesis as proposed by these investigators, different methodology was used. Treadmill walking, rather than cycling, was used to provoke breathlessness; this was based on recent studies showing that breathlessness is more limiting during walking, whereas leg complaints are more common with cycling $[9,10]$. The current study patients exercised at a high intensity $(92 \%$ of peak $V^{\prime} \mathrm{O}_{2}$ on the treadmill) during constant work exercise, in an attempt to provide an adequate respiratory stress or challenge, whereas incremental cycle ergometry of shorter

\begin{tabular}{|c|c|c|c|}
\hline & Naloxone & Normal saline & p-value $(95 \% \mathrm{Cl})$ \\
\hline Baseline & $6.3 \pm 2.0$ & $6.0 \pm 1.8$ & $0.45(-0.46-0.99)$ \\
\hline End-exercise & $19.8 \pm 4.7$ & $19.3 \pm 5.5$ & $0.72(-2.57-3.64)$ \\
\hline $30 \mathrm{~min}$ post-exercise & $8.7 \pm 2.6$ & $7.8 \pm 1.7$ & $0.15(-0.37-2.22)$ \\
\hline
\end{tabular}

duration ( $\sim 5-6 \mathrm{~min})$ was the stimulus in previous studies $[5,6]$. The current study patients reported symptoms continuously throughout exercise; this approach provided several advantages compared with the discrete method [11, 19].

Previous laboratory investigations support the role of endorphins in modifying the perception of breathlessness with respiratory challenges. For example, BELLOFIORE et al. [25] found that six asymptomatic patients with asthma reported higher breathlessness ratings after naloxone compared with normal saline when bronchoconstricted by inhaling methacholine. AKIYAMA et al. [26] reported that 12 healthy young adults had an increase in breathlessness while breathing carbon dioxide after naloxone administration.

As a secondary hypothesis, the current authors proposed that patients would exercise longer with normal saline compared with blockade of the endogenous opioid system. Although 11 out of the 17 patients with COPD exercised longer on the treadmill with normal saline than with naloxone, the difference did not achieve statistical significance $(p=0.058)$. However, the observed difference in exercise duration between conditions (mean difference $1.68 \mathrm{~min}$ ) was comparable with improvements in exercise time observed with bronchodilator medications (compared with placebo) in patients with COPD performing constant work cycle ergometry [27, 28]. The present data suggest an effect of naloxone on treadmill exercise endurance. A larger number of patients would be required to investigate this hypothesis.

Possible mechanisms for the action of opioids in modifying breathlessness are a reduction in $V^{\prime} \mathrm{E}$, a reduction in $V^{\prime} \mathrm{O}_{2}$ and an alteration in the central perception of breathlessness. Figure 2 demonstrates clearly that $V^{\prime} \mathrm{O}_{2}$ and $V^{\prime} \mathrm{E}$ values were identical between naloxone and normal saline conditions, throughout exercise. In addition, the relationship between $V^{\prime} \mathrm{E}$ and metabolic parameters $\left(V^{\prime} \mathrm{O}_{2}\right.$ and $\left.V^{\prime} \mathrm{CO}_{2}\right)$ during exercise was unaltered with naloxone compared with normal saline. These results are consistent with other findings described at rest and/or at peak exercise in patients with COPD [5, 29]. Previous studies also showed that naloxone had no effect on the ventilatory response to hypercapnia in patients with COPD or in healthy subjects upon completion of running a marathon $[18,29]$. As neither ventilatory responses nor $V^{\prime} \mathrm{O}_{2}$ was affected by administration of naloxone, it appears that endogenous opioids alter the central perception of breathlessness. This mechanism is consistent with the observed benefit of using exogenous opioids, such as narcotic medications, for relieving dyspnoea in patients with advanced or end-stage disease. 
One limitation of the current investigation is the modest number of patients studied. As there was variability of individual responses, a larger number of participants may have provided sufficient power to demonstrate a significant difference in exercise endurance between naloxone and normal saline. Although the current authors attempted to recruit additional patients for the study, several individuals declined participation because of their concern about placement of an i.v. catheter and of possible adverse effects of the i.v. naloxone (fig. 1). Another possible limitation is the dose of naloxone used in the present study. The 10-mg dose was selected based on previous investigations $[7,18]$. Based on the body weight of the current patient group $(74 \pm 14 \mathrm{~kg})$, the 10-mg dose generally exceeds the dose of $0.1 \mathrm{mg} \cdot \mathrm{kg}^{-1}$ used by some other investigators $[6,25,30]$. It is possible that a dose of naloxone $>10 \mathrm{mg}$ may have contributed to a greater effect in some patients.

The current results expand our understanding of how natural biological responses can modify breathlessness under the stress of physical exercise. The findings are consistent with the effect of endogenous opioids in relieving pain. Animal studies show that the pain threshold increases after exercise, and this effect can be partially altered by administration of naloxone [21]. In a study of humans, the threshold for dental pain was elevated by $30 \%$ after exercise compared to a control condition [31]. THORÉN et al. [21] proposed that prolonged rhythmic exercise can activate central opioid systems by triggering discharge from mechanosensitive afferent nerve fibres arising from contracting muscles. Whether the relief of breathlessness experienced by patients with chronic obstructive pulmonary disease who perform exercise training as part of pulmonary rehabilitation is mediated, in part, by the endogenous opioid system, requires investigation.

\section{ACKNOWLEDGEMENTS}

The authors would like to thank M.S. Fragala, at the University of Connecticut (Storrs, CT, USA), for assistance in measuring $\beta$ endorphin immunoreactivity.

\section{REFERENCES}

1 O'Donnell DE, Banzett RB, Carrieri-Kohlman V, et al. Pathophysiology of dyspnea in chronic obstructive pulmonary disease: a roundtable. Proc Am Thorac Soc 2007; 4: 145-168.

2 Light RW, Muro JR, Sato RI, Stansbury DW, Fischer CE, Brown SE. Effects of oral morphine on breathlessness and exercise tolerance in patients with chronic obstructive pulmonary disease. Am Rev Respir Dis 1989; 139: 126-133.

3 Woodcock AA, Gross ER, Gellert A, Shah S, Johnson M, Geddes DM. Effects of dihydrocodeine, alcohol, and caffeine on breathlessness and exercise tolerance in patients with chronic obstructive lung disease and normal blood gases. N Engl J Med 1981; 305: 1611-1616.

4 Santiago TV, Edelman NH. Opioids and breathing. J Appl Physiol 1985; 59: 1675-1685.

5 Kirsch JL, Muro JR, Stansbury DW, Fischer CE, Monfore R, Light RW. Effect of naloxone on maximal exercise performance and control of ventilation in COPD. Chest 1989; 96: 761-766.

6 Bertley J, VanVugt DA, Webb KA, O’Donnell DE. Exertional breathlessness in severe chronic airflow limitation (CAL): perceptual responses to endogenous opioid blockade. Am J Respir Crit Care Med 1995; 151: A409.

7 Simon PM, Pope A, Lahive K, et al. Naloxone does not alter response to hypercapnia or resistive loading in chronic obstructive pulmonary disease. Am Rev Respir Dis 1989; 139: 134-138.

8 Santiago TV, Remolina C, Scoles V 3rd, Edelman NH., Endorphins and the control of breathing. Ability of naloxone to restore flow-resistive load compensation in chronic obstructive pulmonary disease. N Engl J Med 1981; 304: 1190-1195.

9 Man WD, Soliman MG, Gearing J, et al. Symptoms and quadriceps fatigability after walking and cycling in chronic obstructive pulmonary disease. Am J Respir Crit Care Med 2003; 168: 562-567.

10 Pepin V, Saey D, Whittom F, LeBlanc P, Maltais F. Walking versus cycling: sensitivity to bronchodilation in chronic obstructive pulmonary disease. Am J Respir Crit Care Med 2005; 172: 1517-1522.

11 Fierro-Carrion G, Mahler DA, Ward J, Baird JC. Comparison of continuous and discrete measurements of dyspnea during exercise in patients with COPD and normal subjects. Chest 2004; 125: 77-84.

12 Murray JA, Waterman L, Ward J, Kraemer WJ, Mahler DA. Role of endorphins in the perception of breathlessness during treadmill exercise in COPD. Am J Respir Crit Care Med 2008; 177: A1000.

13 Rabe KF, Hurd S, Anzueto A, et al. Global strategy for the diagnosis, management, and prevention of chronic obstructive pulmonary disease: GOLD executive summary. Am J Respir Crit Care Med 2007; 176: 532-555.

14 Mahler DA, Waterman LA, Ward J, McCusker C, ZuWallack R, Baird JC. Validity and responsiveness of the self-administered computerized versions of the baseline and transition dyspnea indexes. Chest 2007; 132: 1283-1290.

15 Ofir D, Laveneziana P, Webb KA, Lam YM, O’Donnell DE. Mechanisms of dyspnea during cycle exercise in symptomatic patients with GOLD stage I chronic obstructive pulmonary disease. Am J Respir Crit Care Med 2008; 177: 622-629.

16 Standards for the diagnosis and care of patients with chronic obstructive pulmonary disease. American Thoracic Society. Am J Respir Crit Care Med 1995; 152: S77-S121.

17 Crapo RO, Morris AH, Gardner RM. Reference spirometric values using techniques and equipment that meet ATS recommendations. Am Rev Respir Dis 1981; 123: 659-664.

18 Mahler DA, Cunningham LN, Skrinar GS, Kraemer WJ, Colice GL. $\beta$-Endorphin activity and hypercapnic ventilatory responsiveness after marathon running. J Appl Physiol 1989; 66: 2431-2436.

19 Mahler DA, Fierro-Carrion G, Mejia-Alfaro R, Ward J, Baird JC. Responsiveness of continuous ratings of dyspnea during exercise in patients with COPD. Med Sci Sports Exerc 2005; 37: 529-535.

20 O'Donnell DE, Lam M, Webb KA. Measurement of symptoms, lung hyperinflation, and endurance during exercise in chronic obstructive pulmonary disease. Am J Respir Crit Care Med 1998; 158: 1557-1565.

21 Thorén P, Floras JS, Hoffmann P, Seals DR. Endorphins and exercise: physiological mechanisms and clinical implications. Med Sci Sports Exerc 1990; 22: 417-428. 
22 Moss IR, Scarpelli EM. $\beta$-Endorphin central depression of respiration and circulation. J Appl Physiol 1981; 50: 1011-1016.

23 Santiago TV, Johnson J, Riley DJ, Edelman NH. Effects of morphine on ventilatory response to exercise. J Appl Physiol 1979; 47: 112-118.

24 Murray JA, Waterman LA, Ward J, Baird JC, Mahler DA. Perceptual and physiological responses during treadmill and cycle exercise in patients with COPD. Chest 2008; [Epub ahead of print PMID: 18753470].

25 Bellofiore S, Di Maria GU, Privitera S, Sapienza S, MilicEmili J, Mistretta A. Endogenous opioids modulate the increase in ventilatory output and dyspnea during severe acute bronchoconstriction. Am Rev Respir Dis 1990; 142: 812-816.

26 Akiyama Y, Nishimura M, Kobayashi S, et al. Effects of naloxone on the sensation of dyspnea during acute respiratory stress in normal adults. J Appl Physiol 1993; 74: 590-595.
27 O'Donnell DE, Flüge T, Gerken F, et al. Effects of tiotropium on lung hyperinflation, dyspnoea and exercise tolerance in COPD. Eur Respir J 2004; 23: 832-840.

28 O'Donnell DE, Sciurba F, Celli B, et al. Effect of fluticasone propionate/salmeterol on lung hyperinflation and exercise endurance in COPD. Chest 2006; 130: 647-656.

29 Tabona MV, Ambrosino N, Barnes PJ. Endogenous opiates and the control of breathing in normal subjects and patients with chronic airflow obstruction. Thorax 1982; 37: 834-839.

30 Santiago TV, Sheft SA, Khan AU, Edelman NH. Effect of naloxone on the respiratory responses to hypoxia in chronic obstructive pulmonary disease. Am Rev Respir Dis 1984; 130: 183-186.

31 Olausson B, Eriksson E, Ellmarker L, Rydenhag B, Shyu BC, Andersson SA. Effects of naloxone on dental pain threshold following muscle exercise and low frequency transcutaneous nerve stimulation: a comparative study in man. Acta Physiol Scand 1986; 126: 299-305. 